\title{
Decolonizing the U.S. Health Care System: Undocumented and Disabled after ACA
}

\author{
LISA SUN-HEE PARK, PhD, Asian American Studies, University of California, Santa Barbara \\ ANTHONY JIMENEZ, Doctoral Candidate, Department of Sociology, University of Minnesota \\ ERIN HOEKSTRA, Doctoral Candidate, Department of Sociology, University of Minnesota
}

Corresponding author: Lisa Sun-hee Park

lspark@asamst.ucsb.edu

\begin{abstract}
The Affordable Care Act (ACA) explicitly denies newly arrived documented and undocumented immigrants health insurance coverage, effectively making them the largest remaining uninsured segment of the U.S. population. Using mixed qualitative methods, our original research illustrates the health consequences experienced by uninsured, disabled undocumented immigrants as they navigate what they describe as an apartheid health care system. Critiquing the notion of immigrants as "public charges" or burdens on the system, our qualitative analysis focuses on Houston Health Action, a community-based organization led by and for undocumented, low-income disabled immigrants in Houston, Texas. Engaging a critical migration and critical disabilities studies framework, we use this valuable case to highlight contemporary contradictions in health care and immigration legislation and the embodied consequences of the intersecting oppressions of race, ability, immigration status, and health care access.
\end{abstract}

Keywords: Immigration; health care; public charge; Affordable Care Act; disability

Health is a public good. We don't have immigration reform. We don't have health care reform. We have apartheid. This is an apartheid system.

- Diego, Executive Director of Houston Health Action ${ }^{1}$

\section{Introduction}

The Patient Protection and Affordable Care Act (ACA) explicitly denies public and private health insurance coverage to undocumented ${ }^{2}$ and newly arrived documented immigrants. In the absence of federal immigration reform with provisions for legalization, the estimated 11 million undocumented immigrants currently in the U.S. are expected to become the largest uninsured segment of the U.S.

\footnotetext{
${ }^{1}$ This is a pseudonym of the organization as is all its individual members' names.

${ }^{2}$ Undocumented immigrants are individuals who entered the United States with permission and subsequently lost their lawful status and those who entered without permission. See Kaiser Commission on Key Facts. 2013.
} 
population as ACA implementation unfolds. With its provisions to insure greater numbers of citizens, the ACA reduces federal reimbursement funds for uncompensated care. As a result, the ACA has been contracting the size and scope of the formal health care safety net on which uninsured undocumented immigrants predominately rely (Staiti, Hurley, \& Katz, 2006). This health care safety net includes a system of public hospitals, community health centers, federally qualified health centers, and nongovernmental organizations whose mission is to provide care to people regardless of ability to pay (Lewin \& Altman, 2000).

This paper is part of a qualitative study that examines the impact of the ACA on undocumented immigrants, who almost disappear altogether as a patient population within the health care safety net. This larger study analyzes the effects of ACA legislation and implementation on health care access and provision for undocumented immigrants across five counties in the four US states bordering Mexico. As a qualitative case study, this paper analyzes the long-term health care and unmet health needs of uninsured, disabled undocumented immigrants in Harris County (Houston, Texas). Bringing together critical disability and critical migration studies, we critique the enduring administrative law and antiimmigrant ideology of "public charge," or the characterization of immigrants as non-contributing drains or burdens on the state and its citizenry. In its legacy, public charge has been integral to the U.S. colonial project of building a nation of able-bodied citizens by directly excluding disabled immigrants ${ }^{3}$ from the U.S.

In this paper, we argue that the concept of public charge motivates the continued ineligibility of immigrants for health care coverage under the ACA, thus perpetuating an apartheid or tiered system of health care access and provision in the U.S. We examine the acute marginalization - including the dire material and health consequences - experienced by uninsured, disabled undocumented immigrants

\footnotetext{
${ }^{3}$ Here we are referring to immigrants who do not have citizenship and are at risk for deportation.
} 
through the analysis of the collective experiences and organizing efforts of a non-profit organization that we call Houston Health Action (HHA). The members of HHA are largely Latino, undocumented, and uninsured immigrants who have experienced catastrophic spinal cord injuries, rely on wheelchairs for mobility, and need acute long-term medical care. Using the example of their lack of access to catheters, we expose the virtually nonexistent long-term health care for uninsured, disabled undocumented immigrants.

We contend that the ongoing contraction of the safety net since the passing of the ACA creates systemic conditions wherein undocumented, low-income and uninsured immigrants' designations as public charges are further substantiated, characterizing them as unproductive and therefore disposable or deportable burdens on society. Houston Health Action members use a disability framework to explain their experiences vis-à-vis the health care safety net to actively critique such designations and call into question their non-productive implications. Challenging their characterization as public charges, HHA and its members organize collectively to decolonize the apartheid health system through a variety of tactics, including fundraising and organizing to obtain necessary medical equipment, providing emotional and moral support to each other to fight isolation, raising awareness and maintaining visibility as disabled and undocumented, and advocating for structural change and intersectional social movements for disabled individuals, people without health insurance or access to care, and immigrants.

What remains consistent across formal safety net organizations outside of Houston Health Action is the totalizing treatment of undocumented, low-income immigrants as nothing but a social problem. This study takes a different, critical approach by centering the perspectives of the immigrants themselves. In this way, these individuals and their organization are viewed as important cases from which to understand the complex intersections of health care and immigration policies, particularly during this significant juncture of major federal policy implementation. The timing of this scholarly 
inquiry is particularly apt given the transformations in health policy as part of ACA implementation. At the time of this writing, the federal government has not successfully repealed the ACA, despite numerous attempts, nor has it passed alternate "replacement" health legislation. However, the Trump administration's proposed health policies, combined with the intensification of immigration enforcement, render our arguments about health care access for uninsured, undocumented immigrants even more relevant.

\section{Methods}

Health care access for immigrants across states can best be described as a 'patchwork,' with differing rules of eligibility and patterns of access and organization. For this paper, we focus on the city of Houston, TX, to better understand the state of health care services for those deemed ineligible by the federal health care policy, ${ }^{4}$ paying particular attention to the politics of long-term care for this population. The initial rollout of the Affordable Care Act (ACA) was tumultuous. The seemingly continuously changing rules associated with this major federal policy, in conjunction with sharp variations in individual states' responses, created significant challenges for health care providers. Consequently, the multiple methods for this study were purposively flexible to capture the unpredictability of this process and allow for potentially unforeseen changes. This paper provides a critical policy analysis through a case study to illustrate, in-depth, the impact of federal health care policy in the everyday lives of low-income, undocumented, disabled immigrants in need of long term care.

\footnotetext{
${ }^{4}$ The larger study concentrated on five different counties that have concentrated populations of immigrants: Maricopa County and Pima County in AZ; San Diego County in CA; Bernalillo County in NM; and Harris County in TX. These four states comprise 39\% of the nation's foreign-born population (US Census 2009 American Community Survey). Each state has adopted different policy approaches to immigrants and their access to health care.
} 
Our case, Houston Health Action (HHA), emerged out of a wider study aimed at evaluating the effects of the ACA for undocumented immigrants in four US states along the southern border between 2014 and 2016. We began by identifying safety net hospitals and clinics, and immigrant health advocates, in each of the targeted metropolitan areas that serve large numbers of immigrant patients. The selection of key respondents relied on a combination of sampling procedures. Careful literature, media, and internet searches on immigrant health care access, along with conversations with knowledgeable policy researchers helped identify the initial pool of potential interviewees. Introducing our study as an assessment of institutions' responses to changes in the safety net since the passing of the ACA, we contacted key individuals - administrators, health care providers, and community health advocates - in hospitals, clinics, and community organizations via telephone and email and employed a snowball sampling technique for the recruitment of additional participants. In the first year of the study, we recruited and conducted a total of 42 face-to-face in-depth interviews with health care providers and immigrant advocacy organizations, five of which included representatives from HHA.

Then, a year later, we expanded the number of interviews in order to provide greater depth and breadth of the variety of responses to health care of uninsured low-income immigrants. To do this, we re-interviewed the initial respondents, including those from HHA, to gauge any changes over the year as well as conducted interviews with a greater number of hospital personnel and immigrant community advocates in each county. In all, we conducted 112 interviews for our wider study, 73 of which were based in Houston. Centered topically around the health care safety net, state and local politics, private hospital systems, and the ACA, the interviews ranged from in-depth, structured interviews lasting two hours or more to relatively brief, semi-structured interviews lasting 30 minutes. Most interviews were conducted in small groups of 2 to 3 respondents. 
While the scope of our wider study informs the context and landscape of the health care safety net in which uninsured, low income undocumented immigrants operate, the case of HHA offers the perspectives and experiences of the only organization within our broader study to be led and exclusively operated by undocumented immigrants. We met representatives of HHA in 2014 and again in 2015: first at a public meeting entitled "Health Care for All Texans," which called for supporters of a single-payer health system, and again at the organization's monthly meeting where we met 27 HHA members, all of whom are from Mexico or other parts of Central and South America. Building on the topics we asked of other individuals/organizations across our wider study and following the leads of participants, our interviews with HHA members included discussions about the organization's leadership and activism within and beyond the local community, transnational relations with families in home countries, and health care for undocumented immigrants in particular. The vantage points of HHA members vis-à-vis the health care safety net offered critical analytical leverage that goes beyond describing post-ACA changes to the health care safety net and contributes idiosyncrasies from which to understand the health care system's operation overall and its intersectional impacts of race, immigration status, and disability.

\section{Building a Nation of Able-bodied Immigrants: Public Charge and the U.S. Colonial Project}

In immigration law, public charge provisions allow for the exclusion of immigrants from the U.S. based upon a largely discretionary determination of an individual's potential to become a public burden or "primarily dependent on the government for subsistence" (USCIS, 2009). For over a century, public charge has excluded immigrants perceived to be or to have the possibility of becoming a burden on the state on both economic and medical grounds. It serves as the basis by which immigrants are rendered inadmissible before and upon their arrival as well as illegal and deportable during their residence in the U.S. (Park, 2005, 2011; Hutchinson, 1987; Evans, 1987; Fairchild, 2005; Van Vleck, 
1932). It even allows for the forced removal or deportation of immigrants who are documented as legal residents. In its exercise, public charge operates as a sort of amorphous category, or a "miscellaneous file" (Van Vleck, 1932, p. 54), that excludes immigrants at the discretion of immigration officials. As the foundation of immigration law, public charge governs who is admissible to the country and thus has been central to the U.S. colonial, nation-building project, determining which immigrants are desirable and deserving of inclusion.

In its early stage, during the mass migration of Europeans during the turn of the last century (1892-1920), public charge was the most frequently used category of exclusion. According to historian Martha Gardner (2009), 'Between 1880 and 1924, 'likely to become public charge' provided a catch-all category of exclusion through which vast numbers of immigrants found themselves deported as potential paupers for moral, marital, physical, and economic deficiencies” (p. 89). Immigration legislation during this time established that potential immigrants could be excluded from admission to the U.S. or deported for up to five years after their arrival for becoming a public charge for medical or economic reasons (Fairchild, 2005; Hutchinson, 1987; Higham, 1976; Van Vleck, 1932). Subsequent immigration and welfare legislation since the 1950s, including the most recent immigration reform bill debated in 2013, has reaffirmed the government's powers of exclusion and expulsion on the basis of public charge and asserted that the use of public assistance demonstrates the public charge status of an immigrant (Park, 2005, 2011; Okie, 2007; Viladrich, 2012). As such, public charge has played a fundamental role in the creation of the U.S. citizenry as a nation of immigrants, directly deciding the quality and character of those immigrants who have been included.

A thorough examination of public charge is important for a critical disabilities and migration studies analysis of the ideological conception of immigrants as burdens to the public and the state. The limited scholarly literature on public charge emphasizes the importance of economic and medical issues 
on this notion of immigrants as public burdens. However, Douglas Baynton (2005) argues for the centrality of notions of ability and disability in the administrative implementation of public charge. He argues, "A disability analysis is essential ... to making sense of the depth of anti-immigrant sentiment and the workings of immigration policy at the turn of the twentieth century" (Baynton, 2005, p. 41).

In addition to the administrative law governing who is admissible to the U.S., public charge operates ideologically to produce and maintain the boundaries of deservingness and citizenship for immigrants and, as such, has privileged able-bodied immigrants as potential productive citizens. In determining the deservingness of immigrants, it has helped define the desirable immigrant as a "good industrial citizen: one who would remain healthy, be a useful worker, and not become dependent on the charity of the nation" (Fairchild, 2005, p. 14), in contrast to those who are unproductive, noncontributing burdens or drains on the state. Linked with these notions of deservingness are implicit and explicit characterizations of "good" immigrants as productive and able-bodied, in contrast with public charges as disabled and dependent.

In allowing immigrants to be removed after being present in the U.S. for a number of years, public charge renders deportable immigrants who become "unproductive" for medical or economic reasons. Thus, immigration policy is structured in a way that produces immigrant bodies as disposable. This includes immigrants who develop a disability as a result of an accident or long-term illness as well as those that are no longer able to work due to their age or the toll that years of manual labour takes on their bodies.

Nearly a century later, public charge remains a powerful tool in its strategic ambiguity and quiet location on the outskirts of public notice. It is a statutory provision under the jurisdiction of nonjudicial staff and not subject to oversight by legislatures or courts. While other administrative laws evolved during the twentieth century, public charge determinations remained in a stage of "arrested 
development" as they moved out of public view, limited largely to the confines of American consulates abroad (see also Evans, 1987). As a result, many potential immigrants are denied visas by American consular officials for their likelihood of becoming a public charge without ever setting foot in the U.S.

After considerable pressure from immigrant legal advocates to clarify the ambiguous nature of this law, the U.S. Citizenship and Immigration Services' (CIS) refined the definition of public charge for the first time in 1999. The one-page notice of clarification included this statement: " public charge' means an individual who is likely to become primarily dependent on the government for subsistence, as demonstrated by either the receipt of public cash assistance for income maintenance or institutionalization for long-term care at government expense" (USCIS, 1999). ${ }^{5}$ While the 1999 clarification allayed fears regarding the potential reach of public charge law for some, immigrants who receive cash assistance and/or long-term care were specifically identified as socially burdensome, heightening their status as deportable.

Immigrants' potential health care costs are one of the most frequently cited sources of this burden (Park, 2011). With the passage and implementation of federal health care reform, public charge determinations may increase as hospitals are faced with significantly lower federal reimbursements for care for uninsured and low-income patients. This may lead to immigrants of various statuses avoiding health care institutions as they become increasingly identified with immigration control, ostensibly facilitating the colonial aim of their exclusion from the US and its myriad institutions. Furthermore, disabled immigrants without insurance coverage or legal documents and in need of long-term care are particularly at risk of being deemed public charges for their long-term health care needs.

\footnotetext{
${ }^{5}$ Long-term care refers to a broad set of paid and unpaid services for people who need assistance with daily living activities due to a chronic illness or physical or mental disability. It can also include medical and therapeutic treatment (see Feder, Komisar, \& Niefeld, 2000).
} 


\section{Immigrant Deservingness Under ACA}

In part as a result of the persistence of public charge ideology, health care for immigrants remains a politically volatile issue. Even immigrants that fit the ideal of a "good" immigrant - hardworking, productive, and able-bodied - are still considered to be undeserving of health care due to their non-citizen status. Demographic transformation in the United States due to immigration has precipitated intense political debates regarding the social and economic costs and benefits of immigration. One of the most passionately argued reasons against immigration is the use of health care by those who are undocumented and the alleged related costs of uncompensated care on public hospitals and community health centers. Since 1970, immigration has increased significantly, and as of 2011, there were 40 million immigrants residing in the U.S., comprising $13 \%$ of the total population. Of this population, 11 million are estimated to be undocumented (Migration Policy Institute). As of the end of 2015, 28\% of non-citizens remained uninsured, compared to $9 \%$ of citizens (Garfield et al., 2016). Legal scholars predict that immigrants will become the largest segment of the population without health insurance after ACA is fully implemented (Irshad, 2012).

On the face of it, the federal health care policy should not affect undocumented immigrants at all. Undocumented immigrants were ineligible for health insurance coverage prior to ACA and remain so after ACA. However, with ACA they are not only ineligible for public health insurance and Medicaid but are also restricted from purchasing private health insurance at full cost in state insurance exchanges. And, while low-income undocumented immigrants are not direct beneficiaries of ACA, they are able to voluntarily purchase insurance in the private market outside of state exchanges - in states where one exists - or from an employer-sponsored plan, when available. However, many undocumented immigrants find the costs prohibitive since these products are not federally subsidized, and most low- 
income immigrants work in industries where employer-sponsored insurance is not an option. ${ }^{6}$ Coupled with eligibility restrictions for Medicaid, this policy results in immigrants being three times as likely to be uninsured compared with U.S.-born citizens and less likely to obtain needed care or preventive services. $^{7}$

In a recent health economics study, Brown, Wilson, and Angel (2015) found that excluding undocumented male migrants from Mexico from ACA does not lower medical costs. This is in part because recent migrants are healthier upon arrival than Mexican Americans already residing in the U.S. Given that the Latino population spends less than non-Latino Whites on health care, the inclusion of undocumented immigrants in an insurance pool could help reduce the premiums of all individuals in an insurance exchange. They write, "Rather than being a burden under the [ACA], including immigrants from Mexico could ease premium costs for citizens, at least in the short term, because relatively healthy people are added to the pool lowering pooled costs" (Brown, Wilson, \& Angel, 2015, p. 997). However, public opinion against coverage of undocumented immigrants remains as strong as ever. Apparently, access to health care denotes a "public good" that goes beyond an accounting of economic costs. In their deep and increasing marginalization from health care access, undocumented immigrants are isolated and thereby "disappeared" from the sphere of the "public".

For the majority of undocumented immigrants, health care access is restricted to emergency care and non-emergency health services at community health centers or safety net hospitals (Howland et al.,

\footnotetext{
${ }^{6}$ As an example, the average income for undocumented families in California in 2007 was $\$ 36,000$. However, family plan premiums on the private market in California average \$16,351 annually. See Fortuny, Capps, \& Passel, 2007. Also, large employers are required to offer insurance to full-time employees under the ACA, but the requirement of verification of legal status during enrollment may pose significant barriers for those who are undocumented. See Howland, Pegany, Coleman, \& Connolly, 2014, p. 2.

${ }^{7}$ Federal Medicaid and CHIP eligibility requires that many lawfully present immigrants wait five-years before access. States have the option to eliminate this waiting period for child and pregnant women, but not for other adults. As of January 2013, 15 states have elected this option. However, undocumented immigrants remain ineligible regardless of their length of time in the U.S. (Kaiser Commission on Key Facts, 2013, p. 1).
} 
2014). ${ }^{8}$ Even with their limited access to care, however, non-citizen adults and children are less likely than citizens to seek care from an emergency room. In fact in 2010, immigrants were nearly half as likely as citizens to visit an emergency room for care (Kaiser Commission, 2013). On average, they have lower per capita healthcare costs than U.S. citizens and legal residents. Although undocumented immigrants represent $12 \%$ of the non-elderly adult population, they account for only $6 \%$ of health spending (Goldman et al., 2006). Undocumented immigrants tend to be younger, working adults who are uninsured and resist using health care as much as possible. For many safety net providers, "care for the undocumented is largely contingent on available funding, the commitment of counties to include all of its residents in its health coverage programs, and the capacity of community clinics to serve this population” (Howland et al., 2014, p. 3).

Issues related to long-term health care for uninsured immigrants add significantly greater complexities to this already difficult scenario. The Emergency Medical Treatment and Active Labor Act of 1986 (EMTALA) requires all hospitals that receive Medicaid or Medicare funding to treat a patient experiencing a medical emergency and ensure that their continuing care is adequate, regardless of the patient's ability to pay or citizenship status. Passed in response to public outrage over hospitals "patient dumping" uninsured individuals, EMTALA mandates that hospitals "stabilize" a patient with an emergency medical condition and only transfer or discharge that patient to an "appropriate" medical facility (Irshad, 2012, p. 806). Once a patient is stabilized, federal funds to cover uninsured low-income unauthorized (meaning undocumented and newly arrived documented) immigrant patients end. Consequently, fulfilling the responsibilities of EMTALA is particularly difficult in respect to

\footnotetext{
${ }^{8}$ Safety net providers are health care providers that deliver a significant level of care to uninsured, Medicaid and other vulnerable patients regardless of their ability to pay for those services (Lewin \& Altman, 2000, p. 21). These providers generally include formal institutions such as public hospitals, community health centers, and local health departments. We would also include more informal entities within this category that provide essential services for the health of this population, such as health advocacy organizations like Houston Health Action.
} 
undocumented immigrants with severe injuries since "appropriate" long-term care facilities are nearly impossible to find (see MacKenzie et al., 2012, p. 1790). Some hospitals have resorted to deporting these patients to other countries to avoid these costs (Park, 2017; Nessel, 2012). Others have tried to avoid admitting these patients into their emergency room in the first place and discharged them to family members as quickly as possible. Across the country, health care providers are scrambling to find alternative funding mechanisms to cover the costs of caring for uninsured and low-income immigrant patients (see Park, 2011), including states like Texas, which have not expanded Medicaid under the ACA and face dramatic reductions in funding and reimbursement for the care of this population.

In addition, safety net health care providers are adjusting to significant reductions in reimbursements for their care of uninsured patients. Since millions of previously uninsured patients are now eligible for Medicaid under the ACA, the federal government will dramatically reduce Medicaid Disproportionate Share Hospital (DSH) payments, which are provided to hospitals that care for large numbers of uninsured or Medicaid patients. These funds are crucial in covering health care costs for the indigent, including those with undocumented migration status. Their reduction has resulted in the safety net's gradual, sharper focus on participants of public insurance programs, of which undocumented immigrants cannot partake. Finally, the ACA's long-term care provisions mostly consisted of modest Medicaid changes designed to encourage states to expand home and community-based services (Wiener, 2013). These provisions signal a continuation of long-term care financing's heavy reliance on Medicaid for the last twenty-five years and fail to address long-term care access for any patients, including undocumented immigrants.

Many immigrant health care advocates with whom we spoke expressed concern that the ACA, in its effort to ensure greater access to health care for U.S. citizens, may actually reduce access to care for many non-citizens by isolating them from the general, formerly uninsured population (see Martinez et 
al., 2015). In interviews with community outreach workers across the four states of the larger study, we noted greater marginalization of low-income undocumented immigrants as a patient population for many safety net hospitals and clinics as they focused their attention on those who are eligible for coverage under the ACA. This is particularly so for those immigrants in need of long-term care. A safety net health care administrator in Houston succinctly described the long-term care options for uninsured patients as, "very little and very limited." She added, “...we do our best with what we have. But that's difficult. It's hard to place someone when there's very little places to go."9

\section{ACA Implementation and Immigrant Health in Texas}

Ranked seventh in the country in percentage of foreign-born residents, Texas (as of September 2016) has opposed the implementation of the two most prominent components of the federal Affordable Care Act: 1) the creation of a state level Health Insurance Marketplace or Exchange and 2) the expansion of Medicaid to low-income adult citizens. As part of ACA implementation, each state must decide whether to comply with either of these options. Unlike the other three states along the U.S.Mexico border, Texas decided against both major components of the new legislation. Consequently, the federal Department of Health and Human Services (DHHS) operates a federally facilitated marketplace for Texans. Furthermore, as a result of this decision, Texas is not eligible for federal funds that would have covered $100 \%$ of the cost of Medicaid expansion for the first three years and approximately $90 \%$ in subsequent years. These decisions have left uninsured 1.5 million non-disabled citizen adults below $138 \%$ of the federal poverty level who would have been eligible for health coverage under Medicaid expansion. Because of the partisan resistance to the federal health care legislation, ACA has had limited impact on the uninsured population in Texas.

\footnotetext{
${ }^{9}$ Interview with author, May 2014
} 
As of February 2016, over 1.2 million Texans had enrolled in health insurance through the federal ACA marketplace. Nationwide, 16.4 million uninsured people gained health insurance coverage through ACA, creating the largest reduction in the number of uninsured in four decades. In Texas, the uninsured rate of $27 \%$ in 2013 declined to $24.4 \%$ in $2014 .{ }^{10}$ Healthcare policy experts do not expect significantly greater declines beyond these figures, given Texas' decision not to expand Medicaid, a decision repeatedly reinforced by Governor Greg Abbott (Goodwyn, 2015). In our interviews, a community health worker at a Harris County safety net hospital explained, "What is considered a 'handout' in Texas is considered a healthcare 'entitlement' in California. So, people's perceptions about what should be a basic right in terms of citizenry is not... there's no parity for it in Texas, for a lot of things." 11 This statement not only recognizes the great variability of ACA implementation on the state level but also draws attention to the overall ethos of public assistance in Texas which emphasizes the notion of health care as a "handout," rather than an entitlement. Combined with the politics of Texas as a border state with a high population of immigrants, health care for non-citizens is a particularly contentious issue.

As a result of its refusal to expand Medicaid and to implement the state health exchange, Texas is a unique site for the study of ACA implementation in a border state with considerable uninsured and immigrant populations. Within Texas, Harris County, the third most populous county in the U.S., presents a further paradoxical case for immigrant health care; it is a county with a wealth of medical infrastructure and resources but a significant population of uninsured people and immigrants. Located in Harris County, Houston is the fourth largest city in the country, with approximately 2.2 million residents. From 1970 to 2000, the population of Harris County doubled, largely due to immigration. As a

\footnotetext{
${ }^{10} \mathrm{http} / / / \mathrm{www} . \mathrm{hhs} . g o v /$ healthcare/facts-and-features/state-by-state/how-aca-is-working-for-texas/index.html\#

${ }^{11}$ Interview with author, May 2015.
} 
result, Houston is the most ethnically and culturally diverse area in the nation. ${ }^{12}$ Twenty-five percent of Harris County residents are foreign-born; $70 \%$ of whom are from Latin America and another $21 \%$ are Asian. Harris County is home to an array of primary, secondary, and tertiary health care resources. In fact, the Houston metropolitan region is home to the largest medical center in the world, the Texas Medical Center, with some of the nation's best hospitals and physicians. Describing itself as “an internationally recognized community of healing, learning and discovery," the Medical Center includes 21 hospitals and receives over 7 million visits a year. ${ }^{13}$ Paradoxically, the 2013 U.S. Census American Community Survey indicates that Texas has the highest rate of uninsured persons in the nation, with Houston's uninsured rates exceeding the state average. ${ }^{14}$ Roughly one third of Harris County residents rely on safety net providers, including emergency rooms, for their health care needs. ${ }^{15}$ These safety net providers that work with specific underserved communities include ten Federally Qualified Health Centers (FQHCs), public health and community health organizations and medical school partners (Baylor College of Medicine, UT Medical School at Houston, and UT Houston Health Science Center), and a large network of health care providers under the umbrella of the Harris Health System, a large public health care system in Harris County.

In attempts to mitigate some of the health needs of the uninsured, Harris Health System provides the vast majority of the safety net health care provision in the county, offering primary, specialty, and acute care to uninsured and low-income patients. Harris Health is not only the largest source of health care for low-income and uninsured patients, it is also one of the largest public hospital systems in the country. In addition to operating the three main public hospitals (Ben Taub, Lyndon B. Johnson, and Quentin Mease) in Harris County, Harris Health manages 19 community health centers and numerous

\footnotetext{
12 The State of Health in Houston/Harris County 2015-2016.

${ }^{13} \mathrm{http}: / / \mathrm{www}$. texasmedicalcenter.org

${ }^{14}$ Ibid: p.16.

15 Ibid: p.21.
} 
other clinics and programs situated across the region. In 2016, 91.9\% of patients seen at Harris Health were either uninsured (62.4\%) or covered by Medicaid and CHIP (20.4\%) or Medicare (9.5\%). And $88.8 \%$ of these patients identified as an ethnic/racial minority. ${ }^{16}$ In the past, Harris Health has quietly included undocumented immigrants as part of its patient population but, during the initial implementation stage of ACA, a significant amount of energy and resources were concentrated on the enrollment of eligible patients into ACA. As a result, particular concerns of undocumented immigrants fell further from its central concerns. Yet in the midst of this geographic context, which could be considered ideal in terms of the health and immigration infrastructure and resources, exist a number of community organizations trying, in the face of the contraction of the health safety net under ACA, to meet the health care needs of those who cannot access the formal medical institutions.

\section{Houston Health Action and the fraying Texas safety net}

Within this great medical divide, Houston Health Action (HHA) demonstrates the acute and intersectional marginalization experienced by uninsured, disabled undocumented immigrants in the U.S. at the point at which the expansion of health care coverage (through the ACA) is most dramatic in recent history. A non-profit, independent organization, HHA was founded in 2005 by low-income disabled immigrant residents with spinal cord injuries who lack access to health care and other social services. Most of the organization's members are Latino, undocumented, and uninsured and are largely unable to maintain employment due to their injuries. HHA formed when Harris Health System no longer covered necessary medical equipment, primarily catheters, which for paraplegics who rely on wheelchairs for mobility are vital to their daily health needs.

In comparison to Harris Health, HHA is miniscule. The organization does not appear on any list of safety net health care services, and yet, it is a lifeline for its members. Tomás, a board member of

\footnotetext{
${ }^{16}$ https://www.harrishealth.org/en/about-us/who-we-are/pages/statistics.aspx
} 
HHA, succinctly explained in an interview (in Spanish), "Thank god we have HHA, but living day to day is very difficult." ${ }^{17}$ The organization currently employs one paid half-time staff person and has assisted over 300 disabled immigrants with spinal cord injuries. The fifty members of the organization are dedicated volunteers who meet three times every month to discuss what medical supplies and medications are needed or available, to plan fundraising efforts for these supplies, and to coordinate advocacy efforts to share information with the larger community. HHA's Executive Director, Diego, explained,

We formed after Harris [Health System] denied our care and would not cover basic necessities like catheters, diapers, etc. We began by selling flowers by the side of the street to raise funds. Now, our group provides and distributes catheters [and other medical equipment], fundraise, and organize communities to get the word out about what is happening. Now, even citizens who are insured but can't afford these basic necessities are coming to us. ${ }^{18}$

Diego's statement touches on the issues with long-term care with which disabled citizens and noncitizens alike struggle in Texas. As Harris Health privileges the enrollment of eligible citizens in the ACA, individuals who still cannot afford health care or are undocumented and ineligible for coverage are left to fend for themselves. For the members of HHA, their need for long-term care is incredibly expensive and challenging. In our interview, Diego stated, "We provide both service and community organizing. The current system is not sustainable. We're all volunteers and we need to do so much more. We need to grow and fundraise." ${ }^{19}$ Although HHA works to address its members' health needs as best as it can, Diego acknowledges the limited ability to meet these needs in "current system" which is marked by the absence of health care coverage for their members. In our interviews, HHA members report increasing barriers to emergency care after the implementation of the ACA, and Diego stated that wait times were worsening as was the quality of medical care that HHA members could access through

\footnotetext{
${ }^{17}$ Interview with author, May 2014.

${ }^{18}$ Interview with author, May 2014

${ }^{19}$ Interview with author, May 2014.
} 
emergency rooms and community clinics. For HHA members, their disability coupled with their immigration status make them easy targets for exclusion and even deportation. HHA members' interactions with the formal safety net system (i.e., the Harris Health System) are a constant reminder of this vulnerability. Within the current system, policies require that their medical needs be "emergencies" before they can be treated. In this way, these emergencies and subsequent construction of undocumented immigrants as public charges are manufactured by the health care system itself.

Most HHA members and those they serve were injured in accidents on the job, while others were victims of crime, like one member we interviewed who sustained kidney and spinal damage as a result of being shot during a robbery. Nationally, low-income undocumented immigrants work in some of the most dangerous workplaces. In Texas, construction workers are 4.5 times more likely to be killed on the job than the average worker, making construction work the most dangerous occupation (Worker's Defense Project of Texas, 2013). Incidentally, after farming and agricultural work, construction is the second most popular area of work for undocumented immigrants, ${ }^{20}$ and a number of HHA members sustained catastrophic injuries while working on construction sites. Christine Kovic (2014) makes a compelling argument about the workplace "accidents" suffered by undocumented immigrants, disputing their random nature. "These are more than mere 'accidents;' they point to the unequal and structural violence disproportionately experienced by members of marginalized communities... Workplace injuries, like human rights abuses, are not equally distributed; some bodies are more vulnerable to injury than others" (p. 18). HHA members experience this structural violence along multiple axes.

Compounding the disproportionately higher risk of workplace injuries faced by domestic and foreignborn racial/ethnic minorities in the employment sector (Seabury, Terp, \& Boden, 2016), the health care system sustains, rather than remedies, the injuries of undocumented immigrants. They are denied care on

\footnotetext{
${ }^{20}$ http://www.pewhispanic.org/2016/11/03/occupations-of-unauthorized-immigrant-workers/
} 
the basis of their legal status, that is, until their bodies are rendered medical emergencies, thus fulfilling the narrative of public charge.

Jose's experience offers an example of this phenomenon. HHA member Jose was gravely injured in 1998 when he was struck by a car while biking to work in Houston. The drunk driver who hit him fled the scene and was never identified. As a result, Jose is paraplegic and relies on a wheelchair for mobility. Jose's experience represents the difficulty of accessing health care and obtaining medical supplies experienced by HHA's members and beneficiaries. As such, his story demonstrates the marginalization experienced as a result of his intersectional identity as Latino, as disabled, and as undocumented. Jose explained that one of the most profound and basic changes to his everyday life after his injury is the necessity of urinary catheters. He, like the other members of HHA, generally needs 200 catheters a month, but the cost is prohibitive, as he has little to no income. Without an adequate supply, he is forced to wash and reuse the catheters repeatedly putting him at risk for catheter-associated urinary tract infections (CAUTI).

Although they are relatively simple plastic tubes, catheters are vital to the daily health and wellbeing of HHA members, and a lack of access to an adequate supply of sterile catheters means that they suffer from repeat infections. Denying access to catheters is counterintuitive for those concerned about health care costs. Although it is one of the most common healthcare associated infections in the US, CAUTI can be easily prevented through the use of sterile catheters. Compared to the costs of catheters, medical treatment for CAUTI is astronomical, with each incidence of infection costing thousands of dollars to treat in a hospital (Kennedy, Greene, \& Saint, 2013). When treated under emergency conditions, these costs rise precipitously.

For Jose and others, dealing with infections is a protracted ordeal. As an undocumented immigrant ineligible for health care coverage, Jose has to be near death in order for his condition to be 
warranted an "emergency" to access care in the emergency room. At one point, when Jose visited two different area hospitals, his urinary tract infection was not considered serious enough to be an emergency, and he was turned away. Due to his chronic health issues associated with his injury, Jose finds even the journey to and from the hospital to be excruciatingly painful. Later, when this infection spread to his other organs and he became gravely ill, he was taken by ambulance to the same emergency room that had earlier turned him away, deemed ill enough to receive emergency medical care, and finally given some medical attention for his infection. However, due to his status as an uninsured immigrant, he was released from the hospital without necessary medication, which he could not afford to purchase out of pocket.

Another HHA member, Samuel, described a similar set of events that occurs over and over again for uninsured immigrants with acute long-term health needs. Samuel's persistent catheter-associated urinary tract infections and lack of access to care took a toll on his body, resulting in kidney failure. Samuel now requires regular dialysis yet is deemed ineligible for dialysis except as an emergency. He discussed his continued struggle to obtain long-term care for his acute health needs from the emergency room. In order to get dialysis for his kidney failure that resulted from an untreated CAUTI, Samuel has to wait until his potassium level reaches a critical point before a hospital will treat him, placing himself at risk of coma or death.

In describing the interaction of HHA members with the health system, Diego stated, "'Good health' is defined in such a way that those whose bodies do not conform are not respected. So you get used to living with pain. It's the new normal." ${ }^{21}$ For the members of HHA, their bodies "do not conform" in a number of ways that intersect to produce the marginalization that they experience as uninsured, disabled, and undocumented Latino immigrants. Their struggle with lack of access to health

\footnotetext{
${ }^{21}$ Interview with author, May 2014
} 
care and medical supplies represents the bodily and material consequences of the ideology of public charge that stigmatizes and marginalizes them as dependent, unproductive, and undeserving.

HHA's critique of this system is to denaturalize what Diego describes as "the new normal" by emphasizing the injustice of our current health system and by arguing for health care as a public good and health care access as a social justice issue. Diego argues that the current situation for disabled undocumented immigrants is unjust: "Health is a public good. We don't have immigration reform. We don't have health care reform. We have apartheid. This is an apartheid system."22

This tiered apartheid system of health care is starkly evident in the lack of care for HHA members with acute long-term care needs. Across the U.S., for citizens and non-citizens alike, family and friends are the primary (unpaid) providers of long-term care (Feder, Komisar, \& Niefeld, 2000) and are far cheaper in cost than any other option (Kaye, Harrington, \& LaPlante, 2010). For low-income U.S. citizens with long-term care needs, Medicaid is the primary safety net for long-term care financing, much of which is spent on the relatively small minority of long-term care recipients living in nursing homes. By comparison, health care for uninsured undocumented immigrants is considered an even more threadbare patchwork, and long-term care for this population is virtually non-existent. Without health care coverage, most HHA members are completely dependent on the care provided by family members. Some HHA members do not have family living in the U.S. or in the Houston area, and others have been left without care when their family members have been deported. As such, immigration policy regarding deportation and removal has a significant impact on the health care of these individuals as well as on the health care costs in caring for this population. Consequently, for HHA members, the loss of family is devastating in profound ways. The few members who do not have family are forced to live in "personal care homes" or shelters. This option is seen as least preferable given the seemingly random and wide

\footnotetext{
${ }^{22}$ Interview with author, May 2014
} 
variation in quality of care. The HHA members have witnessed a number of these homes over the years during their regular visits with fellow members. "You can't imagine how bad some of these places are," Raul said (in Spanish). "They are not given proper care. And, they are next to other people with severe mental and physical injuries in a tiny room. There is no rest." ${ }^{23}$ Raul explained that this is what happens when health care resources and family care networks are absent. HHA has supported these members by visiting them and checking in on their care to ensure that their basic needs are met, and as of this writing, no HHA member has been deported.

HHA's project of decolonization and destigmatization occurs on both the personal and structural levels. In addition to providing necessary medical supplies, HHA combats the isolation their members experience on a personal level from being undocumented, disabled, and uninsured by providing the moral and emotional support that is vital for those of their community. Jose explained that members visit each other in hospitals, nursing homes, or personal care homes, wherever they are. "It's about the back and forth, the laughter, and good conversation [they provide each other]," he said. ${ }^{24}$ Diego added, "We're trying to create community, a sense of belonging, for our well-being." When we asked HHA members what they liked about Houston, almost all respondents initially responded with surprised silence. One member broke the silence with "Nada [nothing]". "Why do you stay?" we then asked. Each member replied, "Familia [family]". Others added, "HHA." As part of their project of decolonizing the apartheid health care system, HHA radically re-envisions the family as a community of care that transcends biological relationships, which are the basis of the "productive" capitalist system. They also re-imagine the relationships of care of someone who is able-bodied looking after someone with a disability; rather, HHA members challenge these traditional care structures, asserting the irrelevance of public charge, which deems them "unproductive burdens" on society (Gomez \& Sanchez, 2013). In fact,

\footnotetext{
${ }^{23}$ Interview with author, May 2015.

${ }^{24}$ Interview with author, May 2014
} 
the group is writing a do-it-yourself health care handbook of advice and information for other undocumented and uninsured people with recent spinal cord injuries, discussing topics like where to get care, how to avoid infection, how to take care of scars, and where to find attorneys for those who have been in accidents.

Drawing on traditions of radical self-determination, HHA members refuse to tolerate the apartheid health care system and are working to confront and defy the structures and policies that intersect to render undocumented immigrants and people with disabilities invisible. As their central organizing strategy, HHA addresses the increasing marginalization of immigrant health care access by making themselves visible. Despite the difficulty and pain of mobility and vulnerability of their immigration status, HHA members have made their visibility central in their efforts towards social change. As such, they have been integral to the immigrant rights movement in Houston and across Texas. "Let's face it," Diego explained. "The way things work benefits some people. We need large numbers. We have to frame this as a community issue, beyond an individual issue." ${ }^{25}$ HHA members regularly participate in, and even lead, immigrant rights marches in Houston, representing their demands for greater worker rights, human dignity, and social equality. At the same time, HHA acknowledges the difficulty of working within the "intersection" of immigrant rights and health care access movements. According to Diego, given the range of difficult issues surrounding low-income immigrants, usually a singular concern that seems the most urgent receives all the attention and energy. The HHA members make decisions regarding what actions to take based upon how they might politically articulate their own intersectional experiences and identities. An HHA member explained, "We need long-term campaigns with education about immigrants and health care. We have to keep fighting." ${ }^{26}$ In addition to immigrant rights marches and educational campaigns, HHA members have also traveled to Austin and

\footnotetext{
${ }^{25}$ Interview with author, May 2014.

${ }^{26}$ Interview with author, May 2015.
} 
Washington, D.C. to lobby for disability rights, and they are trying to meet with the current Governor of Texas, Greg Abbott, who is himself paraplegic and uses a wheelchair for mobility.

\section{Conclusion}

Legal scholar Lori Nessel (2012) writes, “Throughout the world, migrant workers perform the most hazardous work for the lowest wages. However, when migrant workers or their family members are injured or become seriously ill and require ongoing medical treatment, they find themselves at the intersection of two unforgiving regimes: immigration and health care" (63). The experiences of HHA and its members' attempts to access the necessary medical equipment and long-term care demonstrate the salience of what Nessel deems the "two unforgiving regimes" of immigration and health care. At the heart of these regimes, the ideology of public charge and its preference for able-bodied immigrants characterizes HHA members as "undeserving" and "unproductive" burdens or drains on the system. In essence, they are the epitome of public charge - a "bad" immigrant - their wheelchairs a graphic symbol of their burdensome status. In politics and policy throughout U.S. history, the good immigrant, on the other hand, is an individual who contributes more to the host nation than they receive (Park, 2011). Good immigrants remain quietly in the shadows and then recede back to their home country when they are no longer productive. Most importantly, a good immigrant is a worker who expects less than what they get, no matter how little. Their gratitude is illustrated by their silent acceptance of the unequal social conditions that structure their lives. In this regard, HHA members are the antithesis of the good immigrant and the embodiment of public charge. Yet it is the prominent visual representation that the organization has made central to their advocacy efforts. Their lives demand a more inclusive understanding of humanity, a message that functions at the core of the larger immigrant and worker rights movement. 
Our study contributes to a critical analysis of the U.S. health care safety net since the passage of the ACA and, responding to calls within critical disabilities and postcolonial literatures, places disability front and center as a decolonizing framework against the contemporary U.S. health care system. Disability operates as both an experiential terrain and a framework uniquely positioned for unraveling and decolonizing the unforgiving apartheid regimes of immigration and health care. These regimes position undocumented immigrants at the fringe of medical considerations for care and the center of immigration deliberations for public charge. Rather than attempting to change their bodily comportment to be reincorporated back into the formal medical sphere, HHA members draw on their bodily experiences to critique and inform the mechanics of intersecting oppressions (see Collins, 2000) operating throughout the U.S. health care and immigration systems. Their goal is not incorporation; it is creation, a radical refashioning of the social environment so that institutions of immigration and health care are beholden to their bodies, and not the inverse.

As immigrants who can no longer function as laborers in the national and local economy, their presence and role in the U.S. poses fundamental questions for key social institutions. For immigration authorities, this population poses a significant conundrum. The HHA members' disability and consequent long-term health care needs classify them as within one of the few explicitly identified categories for public charge and therefore eligible for deportation. For safety net hospitals, whose central purpose is to care for the underserved and vulnerable, the responsibility of on-going care for this marginalized community also requires difficult discussions. Given their persistently constrained resources, safety net hospitals have had to make decisions on how to care - if at all - for this clearly underserved community.

In response, HHA members have made a conscious decision to counter this systemic construction. They have made themselves visible and present in their active and articulate engagement 
of health care, immigration, and disability policy in public events. The presence of HHA members at community events and the incorporation of their experiences at policy events speak to this relationship and subsequently counters simplistic economic responses that will narrowly frame their disability as the larger social problem. And, in line with their intersectional experiences as disabled undocumented immigrants, HHA has explicitly critiqued public charge provisions of immigration law as outdated and discriminatory against those who are disabled.

In sum, the Affordable Care Act has significant impact on undocumented immigrants. Their continued exclusion from the shrinking uninsured population has accentuated their isolation from the public sphere, making them ever more vulnerable. For those undocumented immigrants who are lowincome, disabled, and in need of long-term care, this can lead to dire circumstances. The HHA members have turned this intersection on its head and exposed their own vulnerability to challenge the increasingly intertwined relationship of immigration control and health care provision.

\section{References}

Baynton, D. C. (2005). Defectives in the land: Disability and American immigration policy, 18821924. Journal of American Ethnic History, 24(3), 31-44.

Brown, H. S., Wilson, K. J., \& Angel, J. L. (2015). Mexican immigrant health: Health insurance coverage implications, Journal of Health Care for the Poor and Underserved, 26(3), 990-1004.

Collins, P. H. (2000). Black feminist thought: Knowledge, consciousness, and the politics of empowerment ( $2^{\text {nd }}$ ed). New York, NY: Routledge.

Evans, P. R. (1987). 'Likely to become a public charge': Immigration in the backwaters of administrative law, 1882-1933 (Doctoral dissertation). George Washington University.

Fairchild, A. (2005). Comment: Historicizing the Notion of Disability. Journal of American Ethnic History, 24(3), 45-48. 
Feder, J., Komisar, H. L., \& Niefeld, M. (2000). Long-term care in the United States: An overview. Health Affairs, 19(3): 40-56.

Fortuny, K., Capps R., \& Passel J. S. (2007). The Characteristics of unauthorized immigrants in California, Los Angeles County, and the United States. The Urban Institute. Retrieved from http://www.urban.org/sites/default/files/publication/46376/411425-The-Characteristics-ofUnauthorized-Immigrants-in-California-Los-Angeles-County-and-the-United-States.PDF.

Gardner, M. (2009). The qualities of a citizen: Women, immigration, and citizenship, 1870-1965. Princeton: Princeton University Press.

Garfield, R., Majerol, M., Damico, A., \& Foutz, J. (2016). The uninsured: a primer-key facts about health insurance and the uninsured in America. Kaiser Family Foundation website. Published December, 5.

Goldman, D. P., Smith, J. P., \& Sood, N. (2006.) Immigrants and the cost of medical care. Health Affairs, 25(6), 1700- 11.

Gomez, D., \& Sanchez, J. E. (2013). Public Charge and Disabilities: Toward a More Inclusive Immigration Policy. A Report by Living Hope Wheelchair Association \& Houston United.

Goodwyn, W. (2015). New Texas Governor Adds to Tension Between State, City Governments. National Public Radio. Retrieved from http://www.npr.org/2015/01/15/377526831/new-texasgovernor-adds-to-tension-between-state-city-governments.

Higham, J. (1976). Politics of Immigration Restriction, The. Immigr. \& Nat'lity L. Rev., 1, 1.

Howland, R., Pegany, V., Coleman, C., \& Connolly, J. (2014). Remaining uninsured: A population profile. Insure the Uninsured Project. Retrieved from http://itup.org/wpcontent/uploads/2014/02/Remaining-Uninsured-Groups.pdf.

Hutchinson, E.P. (1987). Legislative History of American Immigration Policy, 1798-1965. 
Philadelphia: University of Pennsylvania Press.

Irshad, N. (2012). Medical Repatriations: Death Sentencing United States Immigrants. Transnational Law and Contemporary Problems, 20(1), 797-824.

Kaiser Commission on Key Facts. (2013). Key Facts on Health Coverage for Low-Income Immigrants Today and Under the Affordable Care Act. Medicaid and the Uninsured. The Henry J. Kaiser Family Foundation. Retrieved from http://kff.org/disparities-policy/fact-sheet/key-facts-onhealth-coverage-for-low/.

Kaye, H. S., Harrington, C., \& LaPlante, M. P. (2010). Long-term care: Who gets it, who provides it, who pays, and how much?. Health Affairs, 29(1), 11-21.

Kennedy, E. H., Greene, M. T., \& Saint, S. (2013). Estimating hospital costs of catheter - associated urinary tract infection. Journal of hospital medicine, 8(9), 519-522.

Kovic, C. (2014). Demanding to Be Seen and Heard: Latino Immigrant Organizing and the Defense of Human Rights in Houston. City \& Society, 26(1), 10-28.

Kovic, C. (2015). Mexican and Central American Immigrant Rights: Local Justice Struggles in a Global City. Working Paper No. 2015-04. Kinder Institute for Urban Research.

Lewin, M. E., \& Altman, S. (2000). America's health care safety net: Intact but endangered. Washington, DC: National Academy Press.

MacKenzie, T. D., Kukolja, T., House, R., Loehr, A. A., Hirsh, J. M., Boyle, K. A., ... \& Mehler, P. S. (2012). A discharge panel at Denver Health, focused on complex patients, may have influenced decline in length-of-stay. Health Affairs, 31(8), 1786-1795.

Martinez, O., Wu, E., Sandfort, T., Dodge, B., Carballo-Dieguez, A., Pinto, R., ... \& Chavez-Baray, S. (2015). Evaluating the impact of immigration policies on health status among undocumented immigrants: a systematic review. Journal of immigrant and minority health, 17(3), 947-970. 
Migration Policy Institute. http://www.migrationpolicy.org/data/unauthorized-immigrantpopulation/state/US. Last accessed May 8, 2017.

Nessel, L. (2012). Disposable workers: Applying a human rights framework to analyze duties owed to seriously injured or ill migrants. Indiana Journal of Global Legal Studies, 19(1), 61-103.

Okie, S. (2007). Immigrants and health care—at the intersection of two broken systems. New England Journal of Medicine, 357(6), 525-529.

Park, L. S. H. (2005). Consuming Citizenship: Children of Asian Immigrant Entrepreneurs. Palo Alto: Stanford University Press.

Park, L. S. H. (2011). Entitled to Nothing: The Struggle for Immigrant Health Care in the Age of Welfare Reform. New York: New York University Press.

Park, L. S. H. (Forthcoming 2017). The Dilemmas of Medical Deportations. In P. A. Kretsedemas (Ed.), Immigration Policy in the Age of Punishment. Columbia University Press.

Seabury, S. A., Terp, S., \& Boden, L. I. (2017). Racial and ethnic differences in the frequency of workplace injuries and prevalence of work-related disability. Health Affairs, 36(2), 266-273.

Staiti, A. B., Hurley, R. E., \& Katz, A. (2006). Stretching the safety net to serve undocumented immigrants: community responses to health needs. Issue brief (Center for Studying Health System Change), (104), 1-4.

The State of Health in Houston/Harris County 2015-2016. Retrieved from http://www.houstonstateofhealth.com/content/sites/houston/SoH-Exec-Summary-2015-2016.pdf

US Census 2009 American Community Survey.

U.S. Citizenship and Immigration Services (USCIS). Fact Sheet: Public Charge. May 25, 1999. http://www.dhs.gov. 
Van Vleck, W. C. (1932). The Administrative Control of Aliens: A Study in Administrative Law and Procedure. Commonwealth fund.

Viladrich, A. (2012). Beyond welfare reform: reframing undocumented immigrants' entitlement to health care in the United States, a critical review. Social Science \& Medicine, 74(6), 822-829.

Wiener, J. M. (2013). After CLASS: The Long-Term Care Commission's Search for A Solution. Health Affairs, 32(5), 831-834.

Worker's Defense Project of Texas. (2013). Build a Better Texas: Construction Working Conditions in the Lone Star State. Austin, Texas. Retrieved from http://www.workersdefense.org/Build\%20a\%20Better\%20Texas_FINAL.pdf. 